\title{
Primitive reflex activity in primary and symptomatic Parkinsonism
}

\author{
JOHN PEARCE, HASAN AZIZ, AND J. C. GALLAGHER \\ From the Combined Neurological Service, Hull Royal Infirmary
}

In the normal subject repeated light tapping over the glabella produces reflex blinking of both eyes. This phenomenon, first described by Overend (1896), has been called the glabella tap sign, the nasopalpebral reflex, the orbicularis oculi reflex, and the blinking reflex; it has been studied by Wartenberg (1945) and by Rushworth (1962). Electromyographic studies (Kugelberg, 1952) demonstrated that this reflex has two components-an initial proprioceptive (myotatic) reflex and a later nociceptive (defence) reflex. Rushworth (1962) has suggested that, where proprioceptive and avoiding reactions are exaggerated, both components of the glabella tap might be accentuated.

A positive glabella tap sign has been used by some neurologists as an early indication of Parkinsonism. In this context however the value of this sign is not widely appreciated. One of the few references is that of Garland (1952) who states 'among the earliest physical signs are those involving the eyes, ... infrequent or absent blinking except on tapping the glabella. This latter is perhaps the most constant and certainly the most characteristic sign. On tapping the glabella both eyelids blink in time with the tapping, whether this be slow or fast, and this blinking will continue indefinitely; the normal person will only blink after the first few taps. For all practical purposes this physical sign is diagnostic of the Parkinsonian state'. However the sign has never been carefully evaluated in a large series of patients with Parkinsonism and with other intracranial diseases.

The present study is an attempt to assess the clinical usefulness of this physical sign and in particular to consider whether or not it has any specificity for Parkinsonism. In the course of this study we have been able to identify a group of patients with destructive cerebral pathology of diverse origins, some of whom on careful scrutiny displayed evidence of secondary Parkinsonism. The significance of the glabella tap sign, of secondary Parkinsonism, and of their radiological and pathological correlates are considered.
METHODS

An unselected series of consecutive patients admitted to the combined neurological-neurosurgical ward at the Hull Royal Infirmary were examined for the presence of the glabella tap sign. To increase the number of patients with Parkinsonism, new out-patients with this diagnosis were included in the study. The ward patients included those with intracranial diseases of all types, and patients with extra-cerebral illness were included as controls. Additional controls were obtained by examining healthy doctors, nurses and auxiliary workers in the hospital.

Each subject was examined independently by three observers. The sign was recorded as being positive, borderline, or negative. Where there was any disagreement the three observers re-examined the subjects together and a final judgment was recorded. The sign was elicited by light tapping with the index finger over the glabella region of the forehead and over the bridge of the nose. Care was taken to avoid reflex blinking from visual threat by ensuring that the examiner's hand was held above the patient's eyes, the finger pointing downwards. A normal response consists of up to five blinks following repeated tapping, further blinking stopping at this point despite continued tapping. The rate of tapping is some importance; some patients continuing to blink if the tapping was slow (two per second), but ceasing to do so with faster rates (greater than five per second). The vast majority of patients clearly fell into positive and negative groups. In a small proportion of cases the result was judged to be borderline; in these patients blinking continued on slow tapping up to 10 times and then stopped, or stopped when the speed of tapping was increased to more than five per second (Fig. 1).

All patients were subjected to a detailed neurological examination, and contrast radiology or pathological study was performed if clinically indicated, and in this way provided more accurate information about the size, site and nature of the cerebral lesion.

\section{RESULTS}

Table I shows that there were 100 patients -76 with intracranial disease and 14 with extracranial disease; 10 healthy subjects served as controls. The mean age of those with intracranial disease was 


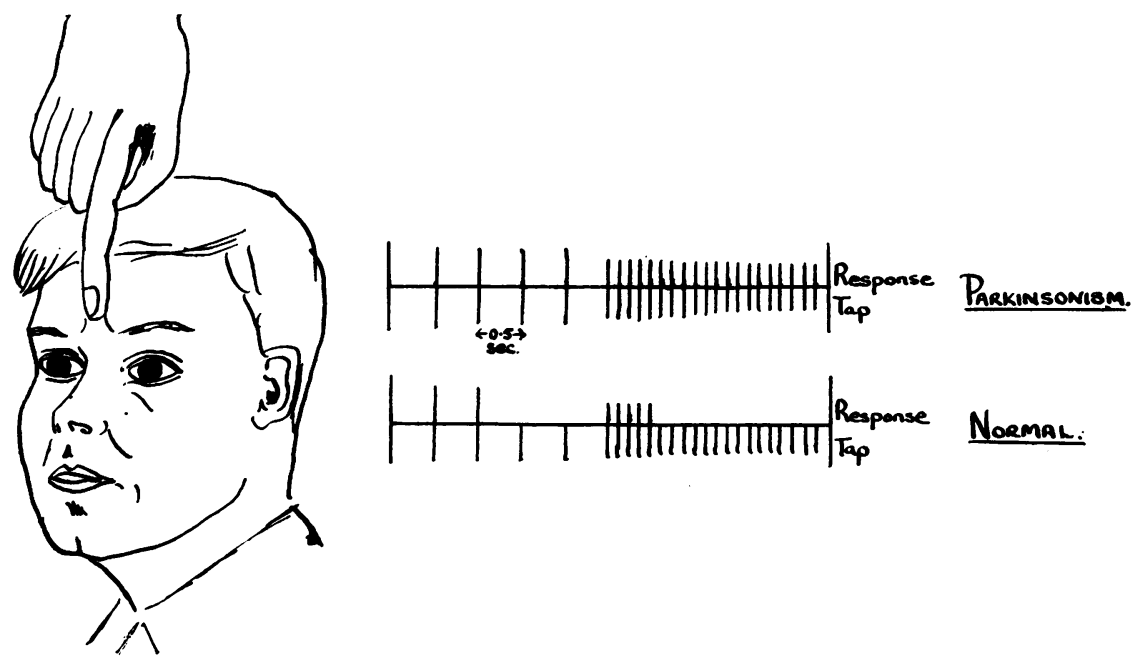

FIG. 1. Glabella tap reflex.

50 years in males and 51 years in females; the mean age of those with extracranial lesions was 46 in males and 45 in females. In the control subjects the mean age was 34 in males and 27 in females. The incidence of a positive sign in patients with extracranial disease (14) and controls (10) was very similar, and these two groups were therefore combined under the heading of controls.

Table II shows that in those with intracranial disease the glabella tap sign was positive in 33 patients, borderline in two patients, and negative in 41 patients. In the control group the sign was borderline in one patient and negative in 23 patients.

The reliability in eliciting the glabella tap sign is illustrated in Table III, which shows the correlation achieved by three independent observers. In those with intracranial disease there was complete agreement in $67(88 \%)$ instances and disagreement in nine $(12 \%)$ instances. In the control group, agreement was achieved in all 24 patients. As this study progressed the amount of disagreement diminished, so that, in the last 20 patients studied, complete agreement was obtained by all three observers.

In those patients recorded as borderline, the observer differing from the other two recorded a positive result in four instances and a negative result in four instances. This shows that there was no particular tendency towards false positive or false negative results.

Theresults in patients presenting with Parkinsonism and in those with other cerebral disorders are shown in Table IV. This demonstrates that in Parkinsonism the glabella tap sign was almost always positive, and was negative on only one occasion. It should be

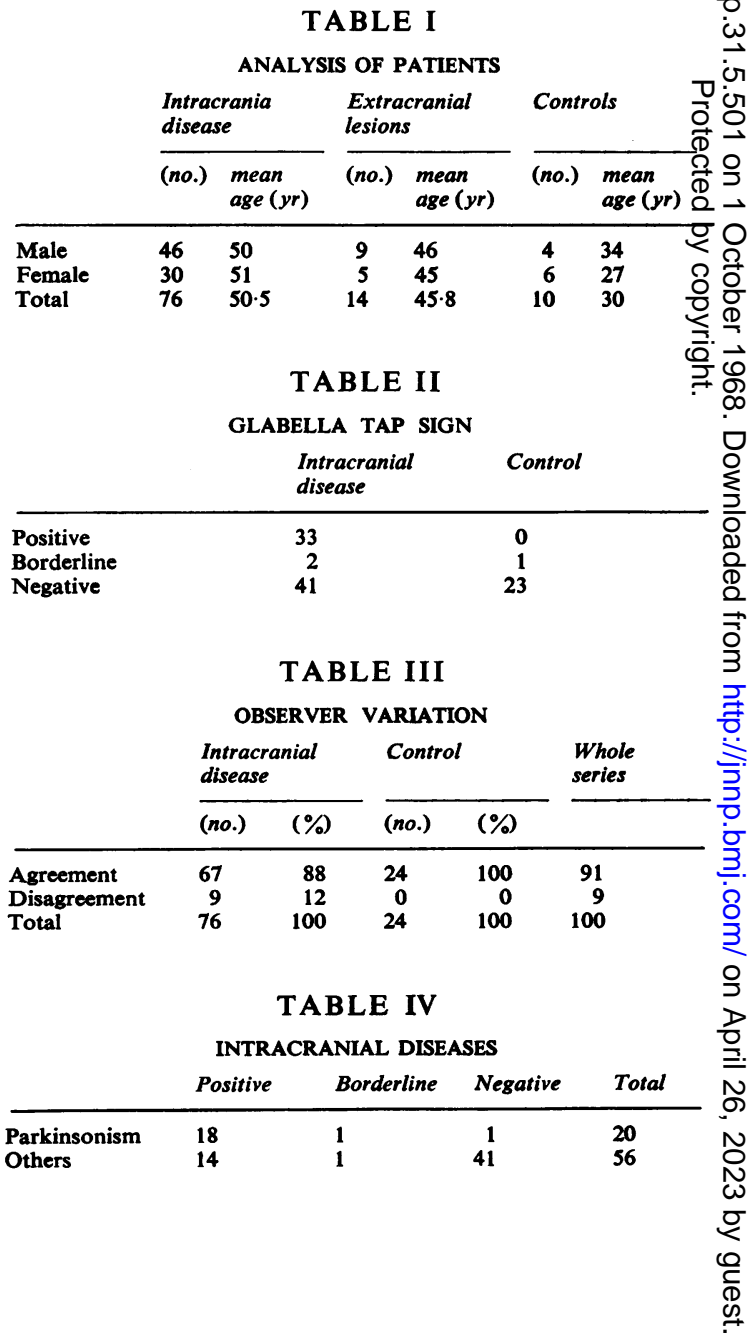


emphasized that these patients were not those incapacitated by advanced Parkinsonism and most patients were in the early stages of the disease having been sent to the out-patient department for diagnosis.

Table V shows the salient features of patients with a positive glabella tap, the primary cerebral lesion being other than Parkinsonism. Of the diverse conditions included in this group, the common identifiable feature was that of widespread destruction or degeneration of brain tissue. The clinical evidence of Parkinsonism is summarized in this Table. It will be seen that, apart from the glabella tap sign, there was definite evidence of Parkinsonism in five patients, and mild Parkinsonian signs other than glabella tap sign were present in three patients.

The results of air encephalographic studies in five patients are shown in Table VI. All of these patients showed at least one feature of Parkinsonism other than a positive glabella tap sign. Since there are still no absolute criteria for the radiological definition of cerebral atrophy, we have presented six different radiological measurements for assessment, using the somewhat arbitrary criteria of normality suggested by Davidoff and Dyke (1946). In all our patients there was ventricular dilatation as seen in abnormal values for measurements $\mathrm{D}$ and $\mathrm{E}$ (Figs. 2 and 3). Excessive pools of subarachnoid cortical air were seen when this area was adequately visualized.

TABLE V

ANALYSIS OF THE 15 PATIENTS SUBJECTED TO THE STUDY

\begin{tabular}{|c|c|c|c|c|c|c|c|c|c|}
\hline \multicolumn{2}{|c|}{ Initials } & \multirow[t]{2}{*}{ Age } & \multirow[t]{2}{*}{$\operatorname{Sex}$} & \multirow[t]{2}{*}{ Diagnosis } & \multicolumn{4}{|c|}{ Secondary Parkinsonian features } & \multirow[t]{2}{*}{ Site and extent of lesion } \\
\hline & & & & & Facies & Tremor & Rigidity & Posture & \\
\hline 1. & S.G. & 65 & $\mathbf{M}$ & Dementia & + & + & + & + & $\begin{array}{l}\text { Severe dementia, Parkinsonism } \\
\text { bronchogenic carcinoma }\end{array}$ \\
\hline 2. & w.S. & 63 & $\mathbf{M}$ & Presenile dementia & + & - & + & + & $\begin{array}{l}\text { Diffuse and symmetrical dilatation of } \\
\text { ventricular system on AEG }\end{array}$ \\
\hline 3. & D.B. & 53 & $\mathbf{F}$ & Alzheimer's disease & + & - & - & - & $\begin{array}{l}\text { Diffuse and symmetrical dilatation of } \\
\text { ventricular system on AEG }\end{array}$ \\
\hline 4. & G.L. & 58 & $\mathbf{M}$ & Epilepsy of late onset & + & - & - & - & $\begin{array}{l}\text { Epilepsy associated with dementia, } \\
\text { dilatated ventricles on AEG }\end{array}$ \\
\hline 5. & C.w. & 57 & $\mathbf{M}$ & $\begin{array}{l}\text { Cerebello-striatal } \\
\text { degeneration }\end{array}$ & - & + & - & - & $\begin{array}{l}\text { Widespread atrophy of cerebellum } \\
\text { and dilatation of lateral ventricles on } \\
\text { AEG }\end{array}$ \\
\hline 6. & R.T. & 37 & $\mathbf{M}$ & Severe head injury & - & $\ldots$ & - & - & $\begin{array}{l}\text { Deeply unconscious for } 2 \mathrm{~d} \text {; right } \\
\text { frontotemporal contusion and } \\
\text { oedema requiring decompression. } \\
\text { Total amnesia } 3 \mathrm{w}\end{array}$ \\
\hline 7. & R.F. & 24 & $\mathbf{M}$ & Severe head injury & - & - & - & - & $\begin{array}{l}\text { Deeply unconscious for } 2 \mathrm{~d} \text {. Amnesia } \\
\text { until the time of death }(3 \mathrm{~m}) \text {. Severe } \\
\text { diabetes insipidus }\end{array}$ \\
\hline 8. & N.W. & 30 & $\mathbf{M}$ & Head injury & - & - & - & - & $\begin{array}{l}\text { Whole of left hemisphere infarcted; } \\
\text { surgical removal of massive areas of } \\
\text { contused brain }\end{array}$ \\
\hline 9. & J.B. & 51 & $\mathbf{M}$ & Glioblastoma multiforme & + & + & + & + & $\begin{array}{l}\text { Right frontal lobectomy } 2 \mathrm{~m} \text { ago. } \\
\text { Readmitted with tremor, dementia, } \\
\text { and motor intranquillity }\end{array}$ \\
\hline 10. & T.M. & 68 & $\mathbf{M}$ & $\begin{array}{l}\text { Secondary cerebral } \\
\text { tumour }\end{array}$ & - & - & - & - & $\begin{array}{l}\text { Large right frontal lobe metastasis } \\
\text { from bronchogenic carcinoma } \\
\text { removed by frontal lobectomy }\end{array}$ \\
\hline 11. & B.A. & 47 & $\mathbf{F}$ & $\begin{array}{l}\text { Subarachnoid } \\
\text { haemorrhage }\end{array}$ & - & - & - & - & $\begin{array}{l}\text { Posterior communicating aneurysm, } \\
\text { operative ligation. No obvious } \\
\text { neurological deficit }\end{array}$ \\
\hline 12. & A.B. & 48 & $\mathbf{F}$ & $\begin{array}{l}\text { Subarachnoid } \\
\text { haemorrhage }\end{array}$ & - & - & - & - & $\begin{array}{l}\text { Middle cerebral aneurysm, operative } \\
\text { ligation }\end{array}$ \\
\hline 13. & F.B. & 40 & $\mathbf{M}$ & $\begin{array}{l}\text { Suppurative } \\
\text { encephalitis }\end{array}$ & - & - & - & - & $\begin{array}{l}\text { Severe diffuse suppurative inflamma- } \\
\text { tion of left hemisphere causing } \\
\text { aphasia and right hemiplegia }\end{array}$ \\
\hline 14. & R.B. & 26 & $\mathbf{M}$ & Anoxic cerebral damage & + & + & + & + & $\begin{array}{l}\text { Two cardiac arrests following over- } \\
\text { dose with barbiturates (suicidal) }\end{array}$ \\
\hline 15. & H.J. & 50 & $\mathbf{M}$ & $\begin{array}{l}\text { Low pressure } \\
\text { hydrocephalus }\end{array}$ & + & + & + & + & $\begin{array}{l}\text { Longstanding hydrocephalus with } \\
\text { diffuse and symmetrical dilatation of } \\
\text { ventricles on AEG }\end{array}$ \\
\hline
\end{tabular}


TABLE VI

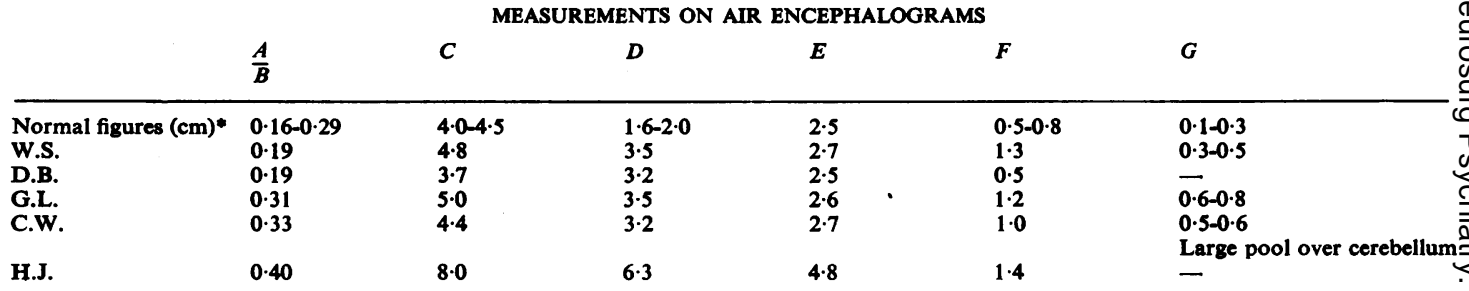

*The normal figures from Davidoff and Dyke, 1946.

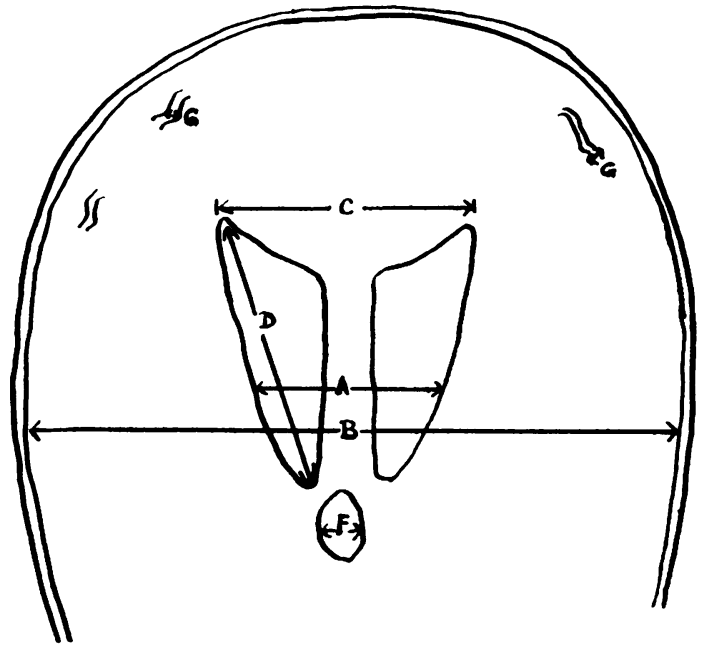

FIG. 2. Air encephalogram, A-P projection. ${ }_{B}^{A}$ ventricular and skull diameters; $C$ and $D$ transverse and diagonal measurements of lateral ventricles; $F$ maximum transverse diameter of third ventricle; $G$ maximum diameter of cortical air spaces.

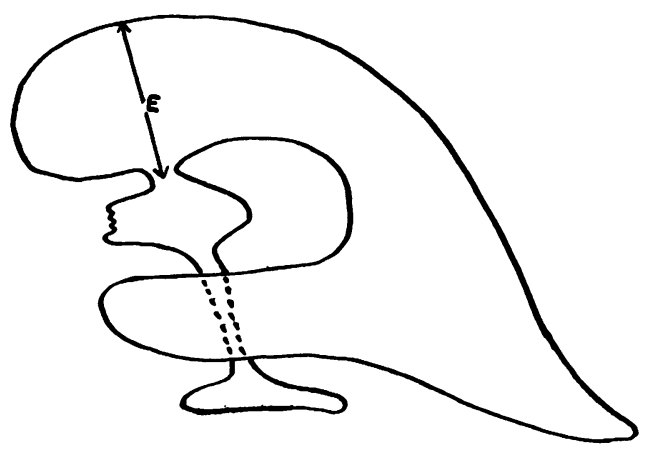

FIG. 3. Air encephalogram, lateral projection. E distance from foramen of Monro vertically to roof of lateral ventricle.
The features of four patients are now described in detail with reference to available radiological and $\frac{\bar{c}}{\widetilde{\Phi}}$ pathological data.

CASE 1

W.S. (H.R.I. D33795), a 63-year-old joiner, was admitted to the unit with a history of progressive weakness of the ${ }^{\omega}$ right arm and unsteadiness of gait. Over the preceding few months he had been getting progressively forgetful and had developed some difficulty with his speech. $\mathrm{He}_{\omega}$ had also complained of some recent severe headaches in the frontal region. On examination on admission he $\mathrm{cr}$ was fully conscious and orientated in time and space, $O$ but his power of calculation had diminished and 1 gis abstract thought was poor. He had mild right-sidgd 5 pyramidal and extrapyramidal signs, but could wafk unaided. He had masked facies, diminished automatic movements, and a positive glabella tap sign. There wgs? mild but definite cog-wheel rigidity in the right arm, but he had no rigidity of his neck muscles.

Investigations showed a normal erythrocyte se mentation rate (ESR) and blood count. The plasma ${ }_{\infty}$ urea and electrolytes were normal.The blood Wasserman reaction (WR) was negative. Cerebrospinal fluid (CSF) contained $30 \mathrm{mg}$ protein $/ 100 \mathrm{ml}$. 1 lymphocyte $/ \mathrm{cu} . \mathrm{mm}$, normal Lange curve, and negative WR. The radiographs $\bar{O}$ of his skull and chest were normal. There was a diffuse bilateral theta rhythm with paroxysms of under- $\stackrel{\odot}{\circ}$ lying generalized delta activity in the electroencephalo- $\underset{F}{\not}$ gram (EEG). An air encephalogram showed symmetrical dilatation of the ventricular system with excessive pools of air over the cortex. With reference to Figs. 2 and 3 . and Table VI, the measurements of parameters D, C, E, $F$, and $\mathbf{G}$ were abnormal.

CONCLUSION (1) Presenile dementia of moderate severity $\frac{0}{7}$ with cerebral atrophy, strongly suggestive of Alzheimer's disease. (2) Definite signs of Parkinsonism.

\section{CASE 2}

J.B. (H.R.I. K27104), a 50-year-old labourer was $\frac{7}{2}$ admitted to the unit with a history of periodic frontal headaches for the preceding two months. His wife $N$ noticed that he tended to fall asleep in the chair and that he had two attacks of loss of consciousness lasting from 
five to 10 minutes. He tended to be clumsy, occasionally incontinent, and he had a very poor memory.

On examination he was found to be ambidextrous, right eyed, left handed and right footed. He was fully conscious. The higher mental functions were preserved. He had bilateral papilloedema, a marked grasp reflex, and a positive sucking reflex. There was no hemiparesis and the tendon jerks were normal; the left plantar response was extensor. Investigations showed a normal haemoglobin, blood count, urea, and electrolytes. The cerebrospinal fluid protein was $40 \mathrm{mg} / 100 \mathrm{ml}$., with one lymphocyte/cu. mm and a negative WR. Radiographs of the skull and chest were normal. A carotid angiogram showed a right frontal lobe tumour which was removed surgically by a right frontal lobectomy and was found to be glioblastoma multiforme.

The patient was readmitted two months later because of increasing confusion and disorientation. Examination showed a Parkinsonian facies with a fixed expression, diminished automatic movements, and a rapid coarse tremor of both upper limbs. Continuous purposeless fidgety movements of both arms were present as seen in the syndrome of 'motor intranquillity'. A brain scan showed a dense concentration of radioisotope in the right frontal region, suggesting a recurrence of the tumour.

CONCLUSion Frontal lobe signs, motor intranquillity, and Parkinsonism developing with recurrence of a large right frontal glioblastoma multiforme.

\section{CASE 3}

R.B. (H.R.I. 19114), a 29-year-old labourer had been suffering from dermatitis herpetiformis for a number of years. He emigrated to Australia in 1966. His skin condition became worse and precipitated a severe reactive depression during which he took an overdose of barbiturate ( 55 tablets of Seconal, $100 \mathrm{mg}$ ). He was admitted to the local hospital. He had severe respiratory failure and while being intubated developed cardiac arrests on two separate occasions responding to intracardiac adrenaline and external cardiac massage. $\mathrm{He}$ was unconscious for four days. On recovery he was found to have become generally stiff, slow in movements, dysarthric, and incapable of looking after himself. Since then this disability has remained unchanged. He was admitted for assessment to the Combined Neurological Service of the Hull Royal Infirmary in 1967.

On examination on admission to the unit he was found to have an extreme degree of dystonia with abnormal hyperpronation and extension of fingers, arms, and legs. He was quite incapable of walking, sitting, standing, or turning himself in bed because of truncal and limb rigidity. He had a Parkinsonian facies, a positive glabella tap sign, but no tremor. There was a severe degree of generalized lead pipe rigidity of neck muscles, trunk, arms, and legs. He had a monotonous low pitched voice with a scanning type of dysarthria.

It was felt that he had sustained severe and irreversible damage to his basal ganglia during the period of respiratory failure and cardiac arrests. Further radiological studies were considered unnecessary, but it is reasonable to assume that there is extensive cerebral atrophy as a result of prolonged anoxia.

CONCLUSION (1) Severe anoxic brain damage predominantly manifest as truncal and limb dystonia, rigidity, and dysarthria. (2) Definite Parkinsonian features overshadowed by major disability.

\section{CASE 4}

H.J. (H.R.I. 10538). This 57-year-old man was first seen in consultation in June 1967, when he had developed unexplained incontinence of urine while being treated for diffuse back and limb pains by an orthopaedic surgeon. At this time he was remote, disorientated, and showed no grasp of current events. In the subsequent weeks he became profoundly demented and withdrawn and continued to be incontinent of urine. The striking finding on neurological examination was a profound truncal apraxia which made it impossible to sit or stand unsupported. He had a mask-like facies, and marked cog-wheel rigidity in the neck and both upper limbs. All volitional movements were performed slowly, and there was an intermittent tremor in both arms.

Full blood count, ESR, radiographs of chest and skull, and numerous investigations for metabolic disorders were within normal limits. The lumbar CSF pressure was $110 \mathrm{~mm}$ and the CSF protein was $10 \mathrm{mg} /$ $100 \mathrm{ml}$. An attempted lumbar air encephalogram was unsuccessful, air failing to enter the ventricular system. An air and Myodil ventriculogram showed enormous dilatation of both lateral and the third ventricales. With reference to Figs. 2 and 3 and Table 6 the measurements of the parameters $\underset{\mathrm{B}}{\mathrm{A}}, \mathrm{C}, \mathrm{D}, \mathrm{D}$, and $\mathrm{F}$ were grossly abnormal. There was a partial stenosis of the aqueduct, which had been responsible for a low pressure, occult hydrocephalus.

A ventriculo-atrial shunt was performed with a low pressure valve. After this procedure the patient made a dramatic recovery with an almost complete reversal of the dementia, and with abolition of his incontinence and inability to walk. Three months later the patient was in excellent health, could walk unlimited distances, and was returning to work. The glabella tap sign had disappeared.

CONCLUSiON (1) Low pressure occult hydrocephalus which had produced dementia, gait apraxia and incontinence. (2) Definite signs of Parkinsonism. (3) Clinical features including those of Parkinsonism reversed by ventriculo-atrial shunt.

\section{DISCUSSION}

CLINICAL ASPECTS OF THE GLABELla TAP REFLEX Wartenberg (1945) has reviewed much of the earlier literature concerning this physical sign. Preferring to call it the 'orbicularis oculi reflex', he stressed the low threshold for its elicitation, and noted the very 
rapid reaction of the orbicular muscles and the bilateral response evoked. Stimuli as different as light, sound, visual threat, and touching the palate could evoke the reflex. Tapping was an effective stimulus over a wide area ranging from the nasal to the frontal and temporal bones. Wartenberg discussed earlier views that the reflex might originate in the periosteum or skin, but rejected these notions asserting that the response was a true muscle stretch reflex.

He reported its diagnostic importance in that it was depressed in peripheral facial palsy, and noted that it was preserved or exaggerated in upper motor neurone facial paralysis. Like Guillain, Alajouanine, and Marquezy (1924) he emphasized its exaggeration in postencephalitic Parkinsonism and stated that this was so constant as to be regarded as a definite sign of Parkinsonism.

PHYSIOLOGY OF THE GLABELla TAP REFLEX The response to tapping the glabella has two electromyographic components-an initial proprioceptive element and a second nociceptive one. The afferent fibres for the reflex are carried, in the majority of individuals, by the first division of the trigeminal nerve (Kugelberg, 1952). However, in a small proportion of normal individuals the afferent pathway lies in the seventh cranial nerve (Rushworth, 1962). The efferent fibres are carried by the facial nerve.

It has been shown that the initial response is myotatic in nature. It has a short latency $(15 \mathrm{msec})$, there are no latency fluctuations, its amplitude is fixed, it has a low threshold, and the reflex shows synchrony. These observations favour the suggestion that this a proprioceptive reflex (Wartenberg, 1945; Kugelberg, 1952; and Rushworth, 1962).

The second component is a defensive response which has a variable latency and is asynchronous. The response to a second stimulus tends to result in a shorter latency and a higher amplitude, which suggests that this is a response to a potentially painful stimulus or an avoiding reflex, and hence has arisen the term 'nociceptive reflex' (Kugelberg, 1952). In a normal individual this reflex characteristically habituates, becoming a response of increasing latency and decreasing amplitude; for clinical purposes in a normal person there is no response to repeated glabella tapping after the first four or five stimuli.

In Parkinsonism both proprioceptive and nociceptive reactions are exaggerated, and both components of the response to glabella tap are very large and of long duration. However, the more characteristic response is the absence of habituation of the nociceptive reflex. The clinically positive glabella tap reflex is shown electromyographically to $\frac{\text { o }}{Z}$ be due to the persistence of the nociceptive response $\stackrel{\mathbb{Q}}{\perp}$ which on repeated tapping on the glabella does not fatigue. It has an identical latency in a particular $\stackrel{\infty}{=}$ patient even up to the fiftieth or hundredth stimulus, $\widehat{0}$ though the amplitude of the response may be some- 0 what reduced (Rushworth, 1962).

DIAGNOSTIC SIGNIFICANCE OF THE GLABELLA TAP SIGN The clinical use of the glabella tap sign in the diagnosis of Parkinsonism and extrapyramidal $\stackrel{5}{S}$ disorders has attracted little attention. Guillain et al. $\overline{0}$ (1924) found this sign to be constant in all cases of $\frac{}{0}$ postencephalitic Parkinsonism, but absent in $\overline{\frac{D}{S}}$ disseminated sclerosis, thalamic, hypothalamic, and $\stackrel{\varnothing}{\overparen{Q}}$ pseudobulbar syndromes. Rushworth (1962) found a positive sign in all 19 cases of paralysis agitans examined electromyographically.

In the present series there were 20 cases of $\overrightarrow{\vec{H}}$ Parkinsonism. The glabella tap sign was negative in one, borderline in another one, and unequivocally positive in 18 of the 20 patients. The majority of these patients, referred for consultation, were in the $\omega$ early stages of Parkinsonism, and our experience ir suggests that this sign is particularly useful in the ir early diagnosis of Parkinsonism when other sigas are minimal.

It was felt important to assess the specificity the glabella tap sign, and for this purpose patients with unselected cerebral lesions wee 0 examined. The glabella tap sign was positive in 19, and borderline in one. In these patients there wa. $\vec{\theta}$ invariably a gross and widespread cerebral pathology such as presenile dementia with gross cerebral ${ }^{\infty}$ atrophy, severe cerebral anoxia, suppurative encephalitis, severe head injury, and cerebral tumour. S The occurrence of a positive sign showed most correlation with the anatomical extent of the lesion. There was no definite relationship between $a \stackrel{\unrhd}{\AA}$ positive glabella tap and the site of the lesion, nor $\overrightarrow{\vec{O}}$ with any specific type of pathological process.

It is evident that the glabella tap sign may be $\underset{\partial}{\partial}$ positive in patients who do not have any other: signs of Parkinsonism. This emphasizes the point that the avoiding reflexes may be exaggerated not only in disorders of the extrapyramidal system but 0 also in other intracranial diseases. It is also clear that 3 . a positive glabella tap in patients presenting with extensive cerebral lesions of diverse aetiology may be an indication of early Parkinsonism. In these 0 cases it occurs as a symptom of the primary cerebral pathology, and therefore the sign is not specific for Parkinson's disease.

SIGNIFICANCE OF GLABELLA TAP SIGN IN ORGANICN BRAIN DISEASE A small but significant number N 
(eight out of 56) of patients with organic cerebral disease showed definite evidence of Parkinsonism. It should be stressed that this was never the dominant clinical feature, and could be easily overlooked unless specific attention was paid to these features. In detecting these signs, the glabella tap reflex was most valuable.

Inspection of Table $\mathrm{V}$ shows that, in all cases with a positive glabella tap and Parkinsonism, there was a widespread and destructive lesion of the cerebral hemispheres. The groups of disorders associated with a positive glabella tap sign included: (1) primary cerebral atrophies and degenerations (patients 1 to 5); (2) head injury with prolonged amnesia and gross hemisphere contusion, haemorrhage, and destruction (patients 6, 7, and 8); (3) cerebral tumour, in both cases with extensive cerebral involvement, or multiple lesions (patients 9 and 10); (4) subarachnoid haemorrhage, with surgical exploration, aneurysmal ligation, and evidence of extensive infarction (patients 11 and 12); (5) a miscellaneous group in which there was considerable loss of cerebral tissue secondary to suppuration, anoxia, and hydrocephalus, respectively (patients 13, 14 and 15). There is therefore no definite indication of any specific type of pathological process which correlates with development of a secondary Parkinsonian syndrome. However, there may be some correlation with an atrophic process.

In attempting to correlate the clinical features with the observed degree of cerebral atrophy shown on air encephalography, certain difficulties are encountered. Measurements of ventricular width, diagonal measurements, and ratios of ventricular to skull size are potentially fallacious. The main difficulties are in standardizing the magnification, in obtaining the same degree of tilt to the head, and in assessing changes which might result from the injection of different volumes of air. Small differences in any of these factors may significantly alter the size of the ventricles on the $x$-ray plate, and this is the main factor causing variation in reported normal valves.

Because of these difficulties we have recorded six different criteria of cerebral atrophy in the five patients studied by air encephalography. The criteria of normality have been the figures quoted by Davidoff and Dyke (1946). From our results we have found that the diagonal measurement of the frontal horn of the lateral ventricle (D) appears to be the most reliable of the criteria we have examined (Fig. 2). The next most reliable measurement appears to be the maximal transverse measurement of both lateral ventricles $(C)$ in the A-P projection. This latter measurement correlates fairly well with measurement $\mathrm{E}$ in Fig. 3, which is the distance 8 from the foramen of Monro vertically to the roof of the lateral ventricle in the lateral projection.

It is not claimed that these criteria are satisfactory, but they do provide measurements which approximate to the ventricular size. We have tried to correlate these results with the clinical severity of the Parkinsonism in the patients studied. There seems to be a trend in which the greater the degree of cerebral atrophy and consequent ventricular enlargement the more frequent and more severe are the stigmata of the Parkinsonian syndrome (Tables V and VI).

Of the eight patients with signs of Parkinsonism additional to a glabella tap sign, six had proven or presumptive evidence of ventricular dilatation or cerebral atrophy. Regarded from another viewpoint, patients $2,3,4$, and 5 all presented features suggestive of a progressive cerebral degeneration as seen in Alzheimer's disease; in all these patients there were observable Parkinsonian features.

It is cogent to question the significance of a positive glabella tap in the absence of other Parkinsonian signs. There are two ways of thinking about this problem.

Firstly, to regard a positive sign as being the first sign of Parkinsonism, in which case all 15 patients presented in this paper would be considered as having early or latent Parkinsonism. In favour of this view is the striking correlation of the sign in established Parkinson's disease (Wartenberg, 1945; Garland, 1952) in which it is rarely absent. Conversely, to prove that a positive sign in isolation is a prophecy of later Parkinsonism would necessitate a careful prospective follow-up study, which to our knowledge has never been undertaken.

Secondly, to regard a positive glabella tap sign as a non-specific sign, common to any destructive cerebral lesion of considerable size, and indicating the release of a primitive developmental reflex. This is the view which we think is most tenable, but it does fail to explain the remarkable correlation with Parkinson's disease-even in its early stages. The reasons supporting this hypothesis require further explanation.

The glabella tap reflex is probably identical with the nasopalpebral, and orbicularis oculi reflex (Wartenberg, 1945). It is closely akin to the reflex blepharospasm found for a few days in newborn infants, and in all premature infants in whom it may persist for up to six months (Fisher, 1963). In the $21.5 \mathrm{~cm}$ foetus Minkowski (cited by Fisher, 1963) observed a reflex contraction of the orbicularis oculi in response to touching the inner canthus of the eye. The primitive nature of the reflex as a normal accompaniment of the developing nervous system is not in doubt. Its appearance in acquired disease of the nervous system can be considered as 
a release phenomenon in the Jacksonian sense of the term. As a positive phenomenon it may be thought to reflect a disturbance of frontal lobe function (Denny-Brown, 1956). Our results strongly support this hypothesis, because extensive and diffuse brain damage was the one finding common to all 15 patients with a positive glabella tap sign. As stated earlier, if one type of pathology was significantly more frequent than any other it was that of cerebral atrophy of a diffuse type as exemplified by Alzheimer's disease.

It is of interest that in an independent, but similar, study Paulson and Gottlieb (1968) have recently reported the reappearance of other developmental reflexes in 85 aged and demented patients. The incidence of these reflexes varied from $7 \%$ to $53 \%$. In order of frequency, the abnormal patterns elicited were reflex sucking, snout, gegenhalten. palmomental, grasp, and corneomandibular reflexes, The glabella tap reflex was not described in this paper. The findings of Paulson and Gottlieb (1968) are complementary to our own results, and we suggest that the finding of a positive glabella tap reflex should be considered as an important but nonspecific sign of extensive structural damage to brain tissue. Why it should appear in Parkinsonism in the absence of cerebral atrophy remains unknown, but it is possible that this occurrence represents an enhanced proprioceptive and avoiding response which are recognized phenomena of basal ganglia disorders (Denny-Brown and Chambers, 1958). If this is the correct explanation, then we are able to recognize two distinct factors which may determine a positive glabella tap sign. First, the release of a primitive reflex by diffuse cerebral damage, and, second, the enhancement of proprioceptive and avoiding responses which complicate degenerative lesions of the globus pallidus and substantia nigra.
SUMMARY

The glabella tap reflex has been studied in 100 patients. Twenty suffered from Parkinsonism, $56 \%$ from other unselected cerebral diseases, and there were 24 controls. An abnormal reflex was found ino 19 of the 20 examples of Parkinsonism and in none of the control group. Fourteen patients with the? cerebral pathology other than Parkinsonism had positive sign, and it is suggested that some of these had latent Parkinsonism secondary to their primary cerebral lesion, which was always extensive in? degree. In the absence of other Parkinsonian signs, a glabella tap sign may indicate the return of primitive reflex activity in response to destructive lesions of the cerebral hemisphere. In this group of patients the glabella tap reflex has been correlatedes with other clinical and air encephalographic signs $\vec{\circ}$ of cerebral atrophy and of Parkinsonism. The possible significance of the results is discussed.

\section{REFERENCES}

Davidoff, L. M., and Dyke, C. G. (1946). The Normal Pneumoence- $\omega$ phalogram, 2nd. ed. Lea and Febiger, Philadelphia.

Denny-Brown, D. (1956). Positive and negative aspects of cerebnglic cortical functions. N.C. med. J., 17, 295-303.

- and Chambers, R. A. (1958). The parietal lobe and behavio Res. Publ. Ass. nerv. ment. Dis., 36, 35-117.

Fisher, C. M. (1963). Reflex blepharospasm. Neurology (Minnea 13, 77-78.

Garland, H. G. (1952). Parkinsonism. Brit. med. J., 1, 153-155.

Guillain, G., Alajouanine, T., and Marquezy, R. (1924). L'exageration du reflexe naso-palpebral dans les syndromes pqsencephalitiques. C.R. Soc. Biol. (Paris), 91, 364-365.

Kugelberg, E. (1952). Facial reflexes. Brain, 75, 385-396.

Overend, W. (1896). Preliminary note on a new cranial reflex. Lan $1,619$.

Paulson, G., and Gottlieb, G. (1968). Developmental reflexes. reappearance of foetal and neonatal reflexes in aged patients. Brain, 91, 37-52.

Rushworth, G. (1962). Observations on blink reflexes. J. Neurol. 으 Neurosurg. Psychiat., 25, 93-108.

Wartenberg, R. (1945). The Examination of Reflexes: A Simplification. Year Book Publishers, Chicago. 